Many receiving staff members were able to describe occasions in which they felt the ward choice was inappropriate for a young person, including when the decision went directly against patient choice.

When asked what factors defined an 'adult lifestyle', both groups expressed similar views, with employment, independent living and being parents themselves comprising the top three responses.

Receiving staff generally reported feeling confident when looking after young people, but few had received any specific training in the last 5 years.

Conclusions The appropriate location of care for adolescents in hospital cannot be effectively determined by anything as simple as an age limit. Whilst age must be considered, other factors also play a major part. By involving young people in making an informed choice, it is hoped that we can make the right decision for each individual. The need for increased training in adolescent health for healthcare staff is also proposed.

\section{G158(P) FROM BEING LOOKED AFTER TO LOOKING AFTER THEMSELVES: DO YOUNG PEOPLE FEEL PREPARED?}

A Yeadon, A Share. Department of Community Paediatrics, Leeds Community Healthcare, Leeds, UK

\subsection{6/archdischild-2015-308599.154}

Aims Smooth and successful transition to adult life is an important focus in care planning for young people who are Looked After. As surrogate parents, local authorities should ensure young people are appropriately prepared and supported throughout this challenging phase. This research sought to gain young people's perspectives on whether this is currently being achieved in our area.

Methods A survey of Looked After young people aged 12-15 years was carried out in 2013, covering various aspects of preparedness for transition and thoughts about the future. Questionnaires were completed by young people either alone or with support from their school nurse. Out of 84 young people eligible, opportunistic sampling resulted in 38 responses.

Results 79\% reported feeling positive about their futures. Many described specific aspects they were looking forward to, often relating to employment and independent living, while 5\% found the prospect of future independence worrying. Many had high aspirations, with nearly half hoping to go to university. Being healthy, earning plenty of money and having children were also popular ambitions.

General 'life skills' education in schools was reported to be mostly helpful (including about healthy lifestyles, smoking and staying safe), with additional advice often obtained from adults outside school. However, information on some topics was viewed less positively, for example around money management and sex and relationships, with a number of young people wishing for more advice in these areas.

In terms of independent health-seeking skills, 82\% reported knowing where to obtain general health advice, but only $69 \%$ knew how to seek sexual health advice. Worryingly, some nurses felt that this question was not relevant to all their young people. Conclusions This research suggests that overall our young people feel well prepared for becoming independent adults. However, not surprisingly, some anxiety still remains. Despite 92\% reporting having enough information to help plan their futures, over a quarter felt they would benefit from additional guidance. As well as offering individualised support, it is important that general 'life skills' education is delivered effectively. Further consultation is required to determine whether schools, carers or professionals are best placed to facilitate this.

\section{Paediatricians with Expertise in Cardiology}

\section{G159 A REVIEW OF THE AVAILABILITY OF PEC (PAEDIATRICIAN WITH EXPERTISE IN CARDIOLOGY) SERVICES IN THE UNITED KINGDOM}

${ }^{1} \mathrm{H}$ Andrews, ${ }^{2} Y$ Singh. ${ }^{1}$ College of Medical and Dental Sciences, University of Birmingham, Birmingham, UK; ${ }^{2}$ The Rosie Hospital, Cambridge University NHS Trust, Cambridge, UK

\subsection{6/archdischild-2015-308599.155}

Aim To determine the availability of PEC services in the UK by investigating the number of non-specialist paediatric cardiology hospitals employing PECs, the number of these holding local PEC clinics and specialist outreach clinics, and the average duration of clinic appointments therein.

Methods An internet-based questionnaire was distributed via PECSIG and NICHe (Neonatologists with Interest in Cardiology and Haemodynamics) databases. Non-responders were followed up by telephone.

Results The response rate was $80 \%$ (141/177 hospitals). Of these, 68\% (96/141) had established PEC services with at least 1 PEC employed and 19\% (27/177) employed two or more PECs per hospital.

Local, PEC-led outpatient clinics were held in all 96 hospitals where at least one PEC was employed. Overall, 47\% (66/141) of hospitals held PEC-led clinics at least weekly, 11\% (16/141) fortnightly and 10\% (14/141) monthly or less frequently. However, $32 \%(45 / 141)$ held no PEC-led paediatric cardiology clinics. The mode time for new patient appointments at the PEC-led clinics was $30 \mathrm{~min}$ (range: $20-45 \mathrm{~min}$ ) and the mode duration for follow-up appointments was $20 \mathrm{~min}$ (range 20-30 min).

Specialist outreach clinics, run with the support of a visiting Consultant paediatric cardiologist, were held in $87 \%(123 / 141)$ of hospitals. The majority of these clinics $(72 \%, 88 / 123)$ were held monthly. 19 hospitals held no specialist outreach clinics and 11 of these hospitals did not hold any local PEC-led clinics either.

Conclusion There has been a substantial increase in PEC availability in non-specialist paediatric cardiology hospitals $(68 \%$ as compared to $35 \%$ in 2008) but still almost one-third (32\%) had no established PEC services. In most but not all hospitals, support was offered by tertiary-centres for paediatric cardiology via specialist out-reach clinics. There remain at least 11 hospitals that neither employ a PEC nor receive any specialist support via outreach clinics.

\section{G160 NEONATAL PULSE OXIMETRY SCREENING: AN EVALUATION OF CURRENT CLINICAL PRACTICE}

${ }^{1} \mathrm{R}$ Hulbert, ${ }^{2} Y$ Singh. ${ }^{1}$ Cambridge University School of Clinical Medicine, Cambridge University, Cambridge, UK; ${ }^{2}$ Cambridge University Hospitals NHS Foundation Trust, Cambridge, UK

\subsection{6/archdischild-2015-308599.156}

Introduction Interest in neonatal pulse oximetry screening (POS) for critical congenital heart defects is increasing. In January 2014 POS was implemented in the Rosie Hospital for all 